\title{
An evaluation of bylaw and policy changes on pharmacy robberies in British Columbia
}

\author{
Martin A. Andresen ${ }^{1 *}$, Elliott Mann ${ }^{1}$, Tarah Hodgkinson ${ }^{2}$, Stephen Thacker ${ }^{3}$ and Bob Nakagawa ${ }^{4}$
}

\begin{abstract}
On 15 September 2015, the College of Pharmacists of British Columbia (BC) implemented a set of by-law and security policy changes in an effort to reduce robberies and burglaries in BC pharmacies. Prior to these by-law and security policy changes, pharmacy robberies were increasing in $\mathrm{BC}$ for approximately 5 years. After implementation, pharmacy robberies decreased significantly. In this paper, we evaluate the potential impact of the by-law and security policy changes on pharmacy robberies in four regions within BC. We find strong evidence supporting that the reduction in pharmacy robberies is a result of this by-law and accompanying security policy changes. Specifically, there was an immediate and substantial drop in pharmacy robberies within Vancouver, with a change in trend (now decreasing instead of increasing) for the Interior and Lower Mainland less Vancouver. These results should be considered support for maintaining these by-laws and security policy changes in $B C$ and potential implementation in other areas of Canada experiencing similar issues.
\end{abstract}

Keywords: Crime prevention, Pharmacies, Robbery, Situational crime prevention

\section{Introduction}

Pharmacy robbery is a growing concern for business owners across Canada (Fraser and Viau 2017). According to Cotter et al. (2015), the use of illicit drugs in Canada is increasing while the methods for obtaining these drugs are diversifying (Felson and Staff 2017). More specifically, in British Columbia (BC), and particularly Vancouver, pharmacy robberies have been increasing for a number of years, necessarily leading to an increase in the availability of illicit narcotics in the city during that time (Carman and Adhopia 2018). Last year, BC experienced over 1400 illicit drug-related overdose deaths, the highest in Canada, with significant increases in 2016 and 2017 (BC Centre for Disease Control 2018; Special Advisory Committee on the Epidemic of Opioid Overdoses 2018); moreover, $\mathrm{BC}$ has almost double the rate of the next highest province and a rate that is three times the national average. Similar drug-related issues have emerged in the United States and Australia (HenriquesGomes 2018; Whelan 2018), making this an important public health issue.

Pharmacies can be perceived as soft targets for robberies, because they contain a large quantity of narcotics (such as opioids), have low levels of formalized security and can promise a large payload in a short period of time. In an attempt to reduce robberies in Vancouver, specifically, and British Columbia, more generally, the College of Pharmacists of British Columbia implemented by-law and security policy changes across the province. These changes came into effect 15 September 2015.

In this paper, we evaluate the impact of these by-law and security policy changes on pharmacy robberies

*Correspondence: andresen@sfu.ca

${ }^{1}$ School of Criminology and Institute for Canadian Urban Research

Studies, Simon Fraser University, 8888 University Drive, Burnaby, BC V5A

156, Canada

Full list of author information is available at the end of the article 
across BC. ${ }^{1}$ We consider pharmacy robberies in four regions across BC: Vancouver, Lower Mainland less Vancouver (to avoid double counting), Vancouver Island, and Interior of $\mathrm{BC}$. These four areas represent a significant proportion of the population of $\mathrm{BC}$. The relatively large regions of Vancouver Island and Interior were necessary for analysis, because of the low frequency of pharmacy robberies in these regions and the corresponding appropriate statistical methods. This study provides an opportunity to evaluate the role of situational crime prevention in preventing commercial robbery. With the emergence of an opioid crisis in North America and the associated increased abuse and trafficking of this class of drugs, this study may prove useful for addressing these issues (Fischer and Rehm 2018; Global Commission on Drug Policy 2017).

\section{Crime prevention, situational crime prevention and (pharmacy) robbery}

Crime prevention ${ }^{2}$ has long been considered more cost effective and socially just public policy than traditional crime control measures such as police, courts, and corrections (Waller 2006). Numerous crime prevention strategies address different aspects of criminal events and/or opportunities including: design against crime, crime prevention through environmental design (CPTED), and situational crime prevention (SCP). Specifically, SCP techniques attempt to reduce crime by increasing the risk and effort and reducing the reward associated with committing that crime (Jeffrey 1971; Clarke 2017) and is considered a useful crime prevention strategy for addressing specific types of crime, their situational contexts, and how the crime is committed. As a consequence, SCP strategies have been applied in a wide variety of crime contexts, have a lot of empirical support, and have been shown to have had a significant impact on crime prevention in practice (Welsh and Taheri 2018; Welsh et al. 2018). SCP has also been applied with success to robbery prevention in commercial contexts (Hunter and Jeffrey 1997).

Situational crime prevention considers 25 techniques that are organized into 5 categories intended to affect offending behaviour: increase the effort, increase the

\footnotetext{
${ }^{1}$ Due to police data availability, we focus on pharmacy robberies, and not pharmacy burglaries-identifying pharmacy-related burglaries across the province was not practical given the nature of the records management system used by the police in British Columbia. Though unlikely, this does raise the possibility of potential displacement from robberies to burglaries that we are unable to measure.

2 Though some of the literature reviewed below uses the broader term of Crime Prevention through Environmental Design, for consistency in the text we use SCP because the crime prevention tactics in this context are largely target hardening and highly situational.
}

risk, reduce the rewards, reduce provocations, and remove excuses (Cornish and Clarke 2003; Clarke 2017). Informed by rational choice theory, SCP considers offenders as rational actors, comparing the costs and benefits of any particular criminal opportunity (Feeney 1986; Clarke 1997). Several evaluation and empirical studies have considered situational crime prevention strategies for convenience stores (Amandus et al. 1995; Hendricks et al. 1999; Exum et al. 2010), liquor stores (Casteel et al. 2004), and fast-food restaurants compared to convenience stores (Exum et al. 2010) and found a reduction in associated crime rates.

Tests of SCP techniques in other commercial settings provide a basis for the current study. Amandus et al. (1995) analyzed risk factors relating to local crime, store location, physical factors of the convenience stores (inside and outside), and store policies for 110 convenience stores in Florida. They found that concealed access or escape routes and the placement of the cash register (at the back or the side of the convenience store) led to statistically significant increases in robbery risk. Hendricks et al. (1999) also examined convenience store robbery risk factors through a matched case-control study of 400 convenience store robberies in 14 jurisdictions within three major metropolitan areas in Virginia. They found that poor cash handling practices increased the risk of robbery, whereas being located in a shopping mall and the presence of bullet-resistant shields decreased robbery risk after controlling for locational factors. In Casteel et al's (2004) study of SCP techniques in liquor stores, they were able to replicate a SCP prevention program that had reduced robberies in 60 convenience stores in Southern California. Prevention techniques included target hardening features, improved cash handling policies, alarms, improved locks on doors, and improved lighting (Casteel et al. 2004). Casteel et al. (2004) found statistically significant reductions in crime over the intervention period, with reductions of $82.2 \%$ in robbery and $87.1 \%$ in shoplifting.

Though pharmacies experience crime much like any other commercial establishment, little research has been conducted on the characteristics specifically related to pharmacy crimes. This is important because pharmacies have differing, and arguably unique, security needs because their business practices involve the sale of prescription drugs and narcotics. In response to the increases in pharmacy robbery, mentioned above, many pharmacies throughout North America have recently introduced modern security features that reduce the suitability of pharmacies as ideal targets for robbery or burglary, such as closed-circuit television, time-locked safes, physical barriers, and reinforced locks on doors and windows (LaVigne and Wartell 2015). 
An Office of Community Policing Services (COPS Office, US Department of Justice) report in 2015 provides an overview of pharmacy robberies in the United States, with specific crime prevention measures based on situational crime prevention techniques (LaVigne LaVigne and Wartell 2015). Consistent with SCP, this report suggests three categories of measures that may be taken to reduce pharmacy robbery: increasing the risk of detection, increasing the effort to commit a robbery, and decreasing the susceptibility to robberies. The recommended steps taken to increase the risk of detection include (1) informing pharmacy employees about robbery trends, (2) providing prevention guidelines to pharmacy employees, (3) managing risk factors, (4) installing a panic alarm, (5) using video surveillance, (6) tracking the stolen drugs or offender, and (7) using deterring signage. These techniques can modify employee behavior and the built environment to reduce criminal opportunity. Additional preventative measures include increasing lighting, locking up narcotics, limiting the amount of narcotics available, installing physical barriers, and ensuring that front windows are clear to improve surveillance (LaVigne and Wartell 2015). While not all of these recommendations proposed by the report have been evaluated for their implementation within pharmacies, several techniques have shown to be successful in reducing robberies within convenience stores. Specifically LaVigne and Wartell (2015) found that the best measures for preventing pharmacy robberies include: security camera systems, time-locked safes, physical barriers, and reinforced locks on doors and windows. Guidelines such as these prove instructive for the establishment of policies to reduce pharmacy robberies, more generally.

In the current study, when considering robbery prevention, SCP is likely most appropriate for increasing the effort and increasing the risks. Increasing the effort may include such security measures as target hardening (time-lock safes) and access control that make it more difficult or time consuming to commit an offense, whereas increasing the risks may include such security measures as surveillance (security cameras) and place management.

\section{Changing pharmacy bylaws and security policies}

In British Columbia, the College of Pharmacists of British Columbia established a set of by-law and security policy changes (15 September 2015) based on situational crime prevention techniques in an effort to reduce the rise in robberies and burglaries in $\mathrm{BC}$ pharmacies. The security aspects of the Pharmacy Operations and Drug Scheduling Act-BYLAWS (hereafter referred to as Bylaws) and the Professional Practice Policy-74 (security policies) are identified here. The Bylaws, Community Pharmacy
Security Section 11.1, states that a community pharmacy must have the following security measures:

- A locked metal safe with a time delay set at a minimum of $5 \mathrm{~min}$ for the storage of narcotics and controlled drugs,

- A security camera system that is checked daily for proper operation and has date/time stamped images that are archived and available for at least 30 days,

- Motion sensors in the dispensary,

- a Monitored alarm in the dispensary area if a full pharmacist is not present at all times and the location is accessible to non-registrants,

- Physical barriers to protect schedule I and II drugs, controlled drug substances, and personal health information, if a full pharmacist is not present at all times and the location is accessible to non-registrants,

- Signage that states the presence of a video surveillance system, limited targeted drugs are on site, and that narcotics are stored in a time-delay lock safe, and

- Community pharmacies that existed prior to $15 \mathrm{Sep}$ tember 2015 had 3 years to comply with the Bylaws. ${ }^{3}$

It is also important to note that physical barriers, as well as a monitored alarm within the dispensary area, were only required when a full pharmacist was not present and the location is accessible to non-registrantsin most cases this is when a pharmacy was closed. This would include commercial retailers that close the pharmacy component of their retail outlet and remain open to the public for other retail items.

\section{Data and methods}

\section{Police data}

The data for this study were provided by the Vancouver Police Department. These data include all robberies that occurred in British Columbia. Robberies are then organized into four locations: Vancouver, ${ }^{4}$ Lower Mainland less Vancouver, Vancouver Island, and Interior. Variables include the monthly counts of pharmacy robbery, organized by the four regions created for the Province. For the City of Vancouver, data began in January 2001, whereas the data for the other three locations (Lower Mainland

\footnotetext{
${ }^{3}$ Because of the consultation process between the College and its members, we were informed by the College that compliance with the by-law and security policy changes was undertaken by the vast majority of its members by the implementation date. As such, we modeled the evaluation with the specified implementation date.

4 The exact location of each pharmacy robbery was provided for the City of Vancouver, potentially allowing for a spatial analysis within the City of Vancouver, but there were so few incidents after 15 September 2015 that these few locations cannot be analyzed to obtain useful information.
} 
less Vancouver, Vancouver Island, and Interior) began in January 2006. All regions include robbery counts until April 2017.

\section{Statistical methods}

A structural break test was used to analyze the impact of the by-law and security policy changes. Structural break tests are a type of regression analysis commonly used in pre-post evaluation in economics, but more recently in criminology as well (Hodgkinson et al. 2018; Reid and Andresen 2014; Piehl et al. 2003). This type of regression is instructive for evaluating an intervention with a known date because it includes variables measuring the overall trend in the data as well as (potential) changes in that trend after an intervention was implemented. In structural break tests, a number of control variables are created to account for potential spurious findings, with count data models being popular for "rare event" data such as criminal events (Gardner et al. 1995; Groff and Lockwood 2014; MacDonald and Lattimore 2010; Osgood 2000). Because of the over- dispersed nature of the data, we used the structural break tests within a negative binomial regression (Cameron and Trivedi 1990), controlling for a number of other factors to avoid interpreting spurious results.

A break variable (bylaw) is developed to compare before and after the intervention. This variable is usually categorized as zero for each time point prior to the intervention and one for each time point after the intervention. This variable tests for a change before and after the intervention of both by-law and security policy changes. A break trend (bylaw trend) variable is also created that increases or decreases after the intervention of by-law and security policy changes to test for a change in trend. Two trend variables are included to account for the international decline in crime (trend and trend-squared) (LaFree 1999; Levitt 2004; Farrell et al. 2011; Farrell and Brantingham 2013)), seasonal effects (Harries et al. 1984; Linning et al. 2017) are controlled for with two additional variables (month and month-squared), and the number of days in the month (number of days) is included as a control variable to account for increased robbery risk in months that have more days.

Two variables represent the time period of the intervention, by-law and security policy changes. The first variable is a dichotomous (dummy) variable, valued at zero prior to 15 September 2015, and one after; the second variable is a trend variable for the same time period that takes on consecutive values $(1,2,3, \ldots)$ from $15 \mathrm{Sep}$ tember 2015 forward, and zero otherwise. ${ }^{5}$ The estimated

\footnotetext{
${ }^{5}$ Because the by-law and policy changes began in the middle of September 2015, the bylaw and bylaw trend variables take the value of 0.5 that first month, then sequentially starts from 1.
}

parameters for these two variables will identify if there is an immediate change in the number of pharmacy robberies (the dichotomous variable) as well as continued changes over time (the trend variable).

\section{Results and discussion}

The bi-annual counts of pharmacy robberies are shown in Fig. 1, April-September and October-March are the first an second data points for each year in Fig. 1 with a vertical line marking October 2015-March 2016: from 2001 for Vancouver and from 2006 for the other three regions. The results for Vancouver show a low and flat trend from 2001 to 2006, followed by a steady increase, with a notable increase in 2013, until 2014. The decline in pharmacy robberies appears to begin in 2014, a year prior to the by-law and policy changes. However, in 2013, Vancouver had an unusual number of pharmacy robberies in April and July, such that if these 2 months had the expected value of pharmacy robberies the notable increase in 2013 effectively disappears, and disappears in 2013 (October 2013-March 2014). This anomaly can be attributed to the difficulty of analyzing rare events. The pharmacy robbery counts in Vancouver, however, continued to decrease through to the end of the study period, March 2017.

Lower Mainland, less Vancouver, demonstrates a more volatile trajectory over time. There appears to be an unstable but decreasing trend from 2009 until 2017. Vancouver Island, despite an increase in 2008 and 2009, has a relatively stable trend over the entire study period. And the Interior steadily increases from 2006 until 2014, with a minor decline in 2015 and 2017. Overall, these patterns appear to be consistent with the by-law and security policy changes regarding security for Vancouver and the Interior, all showing near-zero counts for the last three 6-month time periods. However, the Lower Mainland less Vancouver and Vancouver Island do not demonstrate similar trajectories.

In order to provide a comparison to overall robbery patterns, robberies in Vancouver and the Lower Mainland less Vancouver are presented in Fig. 2, 1998 to 2017, with a vertical line indicating 2015 . Over this entire time period, robbery in Vancouver has consistently been decreasing, counter to the pharmacy robbery temporal trend that increased after 2006. Similarly, Lower Mainland less Vancouver exhibits a steady decreasing trend from 2006 forward, unlike pharmacy robbery. Though not a true control, showing these trends indicates that pharmacy robberies diverged from the overall robbery trend and are crime type specific-Vancouver Island and Interior are not shown here because of their low counts.

The results of the negative binomial regression analyses are shown in Tables 1, 2, 3, 4. Table 1, the results for 


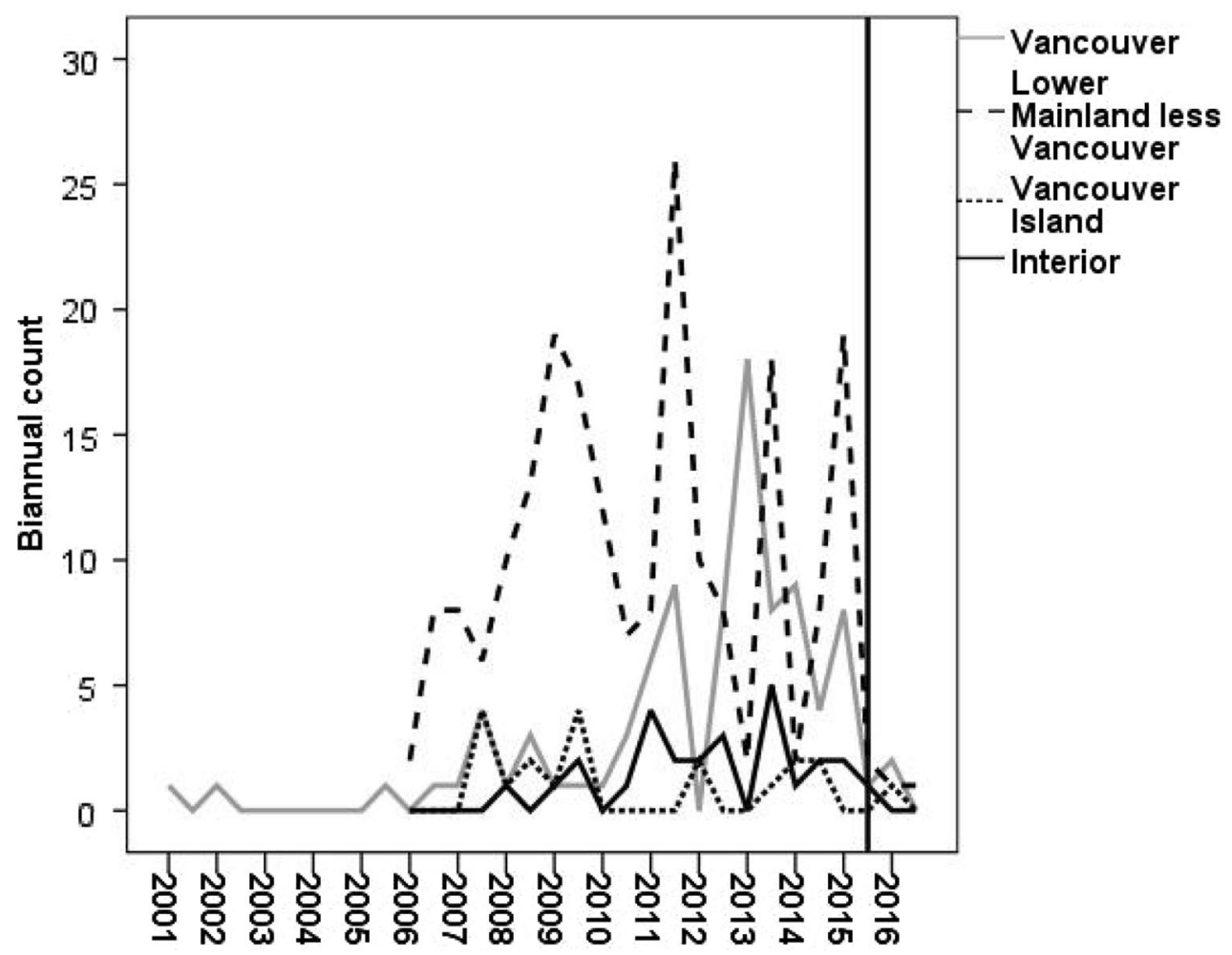

Fig. 1 Pharmacy robbery counts, 2001-2016

Vancouver, are consistent with the trend shown in Fig. 1. In the full model that includes all explanatory variables, whether they are statistically significant or not, the variable representing the by-law and security policy changes (bylaw) are statistically significant and negative: the relative risk ratio (RRR) is 0.167 , indicating $83 \%$ decrease in pharmacy robberies resulting from the bylaw and security policy changes. In the final model, that only included the remaining statistically significant variables, the bylaw variable remains negative and statistically significant, indicating a $94 \%$ decrease in pharmacy robberies resulting from the bylaw and security policy changes. ${ }^{6}$

Turning to the results for the Lower Mainland less Vancouver, Table 2, none of the variables in the full model were statistically significant at the $10 \%$ level (p-value $\leq 0.10)$, a common threshold for statistical significance. $^{7}$ However, when the general-to-specific

\footnotetext{
6 The immediate drop in Vancouver may be due to anticipatory benefits from early advertizing of the bylaw and security policy changes (Smith et al. 2002). However, we have no information regarding the publicity timing or intensity to test this possibility.

7 Whether a 10 , or more common, $5 \%$ threshold is used in our analyses, the qualitative results are almost always the same. Only for the Interior is there an impact on the statistical significance of the bylaw/policy-related variables.
}

testing methodology $y^{8}$ is employed, the bylaw trend variable becomes statistically significant, representing a monthly decrease in pharmacy robberies of approximately $20 \%$. Over time, a notable drop pharmacy robberies in the Lower Mainland is expected.

The results for Vancouver Island, Table 3, are essentially the same for the full model as Lower Mainland less Vancouver: all estimated parameters are statistically insignificant. Once the removal of statistically insignificant variables was undertaken, neither of the by-law and security policy changes regarding security variables remained statistically significant; only trend and trendsquared are statistically significant in the final model.

The results for the Interior, Table 4, show the result indicated from Fig. 1. In the full model, bylaw trend, as well as trend and trend-squared (accounting for the crime drop), are statistically significant. With regard to bylaw

\footnotetext{
${ }^{8}$ A general-to-specific testing methodology "tests down" from the full model with all variables initially in the model. Variables are removed one at a time based on significance levels (variables with high p-values are removed first), with joint singificance tests used to ensure against omitted variable bias. The methodology was employed to prevent the removal of variables that matter for the results but are statistically insignificant because of multicollinearity.
} 


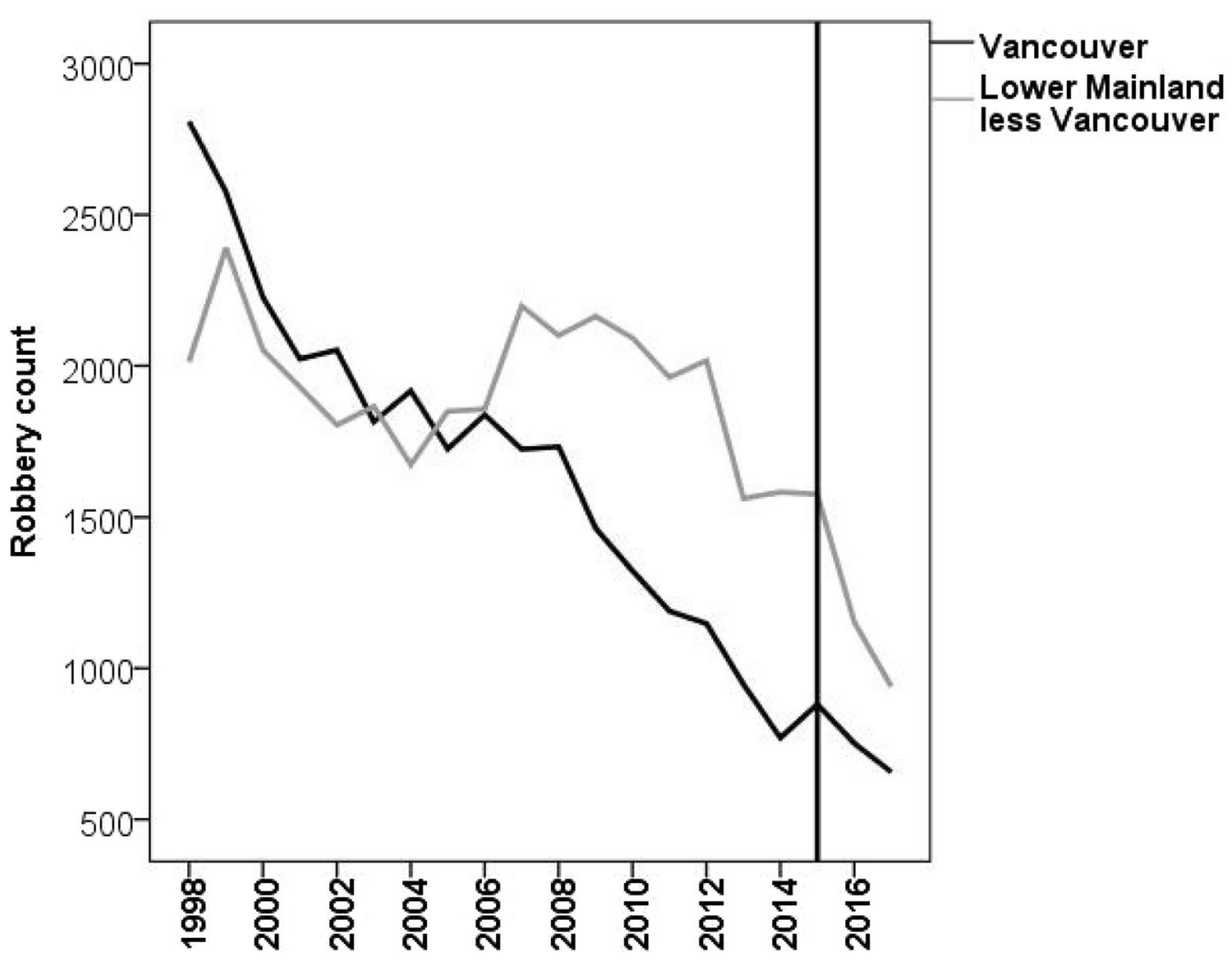

Fig. 2 Robbery counts, 1998-2017, Vancouver and Lower Mainland less Vancouver

Table 1 Negative binomial results, full and final models, Vancouver

\begin{tabular}{lcll}
\hline & $\begin{array}{c}\text { Estimated } \\
\text { parameter }\end{array}$ & Std. error & $\begin{array}{l}\text { Relative } \\
\text { risk ratio }\end{array}$ \\
\hline Full model & & & \\
Bylaw & -1.781 & 0.729 & $0.168^{* *}$ \\
Bylaw trend & -0.112 & 0.081 & 0.894 \\
Month & -0.082 & 0.153 & 0.921 \\
Month-squared & 0.002 & 0.012 & 1.002 \\
Number of days & 0.262 & 0.151 & $1.300^{*}$ \\
Trend & 0.037 & 0.024 & 1.038 \\
Trend-squared & 0.000 & 0.000 & 1.000 \\
Final model & & & \\
Bylaw & -2.829 & 0.613 & $0.059^{* * *}$ \\
Trend & 0.026 & 0.003 & $1.026^{* * *}$ \\
\hline
\end{tabular}

Policy change variables (Bylaw and Bylaw trend), seasonality variables (Month and Month-squared), and overall trend variables (Trend and Trend-squared)

${ }^{*} p<0.10$; ${ }^{* *} p<0.05 ;{ }^{* * *} p<0.01$

trend, every month there is a $20 \%$ decrease in pharmacy robberies. After the removal of statistically insignificant variables, bylaw trend remained statistically significant representing a 19\% decrease in pharmacy robberies each month attributable to the by-law and security policy changes regarding security; it is important to note here that this effect would be considered statistically insignificant if we used a $5 \%$ statistical significance threshold.

\section{Conclusion}

In response to rapid increases in the volume of pharmacy robberies and burglaries, we evaluated the impact of the by-law and security policy changes regarding security using police data on pharmacy robbery. Analyzing monthly counts of pharmacy robbery in four police regions in British Columbia we found that there was an immediate drop in pharmacy robberies in Vancouver that corresponded to the by-law and policy changes, and a decrease in the trend within the Lower Mainland less Vancouver and the Interior that corresponded to the bylaw and security policy changes. Although we cannot claim causality because of the study design, the timing of the changes in the trends of pharmacy robberies correlates with the changes in the by-law and policy changes. We also contextualized our findings with local police leaders, who confirmed that there had not been any 
Table 2 Negative binomial results, full and final models, Lower Mainland, less Vancouver

\begin{tabular}{lcll}
\hline & $\begin{array}{c}\text { Estimated } \\
\text { parameter }\end{array}$ & Std. error & $\begin{array}{l}\text { Relative } \\
\text { risk ratio }\end{array}$ \\
\hline Full model & & & \\
Bylaw & -0.633 & 0.658 & 0.531 \\
Bylaw trend & -0.125 & 0.108 & 0.882 \\
Month & -0.048 & 0.145 & 0.953 \\
Month-squared & 0.004 & 0.01 & 1.004 \\
Number of days & -0.091 & 0.121 & 0.913 \\
Trend & 0.029 & 0.018 & 1.030 \\
$\quad$ Trend-squared & -0.001 & 0.001 & 0.999 \\
Final model & & & \\
Bylaw trend & -0.228 & 0.087 & $0.796^{* * *}$ \\
\hline
\end{tabular}

Policy change variables (Bylaw and Bylaw trend), seasonality variables (Month and Month-squared), and overall trend variables (Trend and Trend-squared) ${ }^{*} p<0.10 ;{ }^{* *} p<0.05 ;{ }^{* * *} p<0.01$

Table 3 Negative binomial results, full and final models, Vancouver Island

\begin{tabular}{lcll}
\hline & $\begin{array}{l}\text { Estimated } \\
\text { parameter }\end{array}$ & Std. error & $\begin{array}{l}\text { Relative } \\
\text { risk ratio }\end{array}$ \\
\hline Full model & & & \\
Bylaw & 0.089 & 1.688 & 1.094 \\
Bylaw trend & -0.088 & 0.071 & 0.916 \\
Month & -0.525 & 0.433 & 0.591 \\
Month-squared & 0.041 & 0.033 & 1.042 \\
Number of days & -0.101 & 0.364 & 0.904 \\
Trend & 0.028 & 0.027 & 1.029 \\
Trend-squared & -0.001 & 0.001 & 0.999 \\
Final model & & & \\
Trend & 0.036 & 0.022 & $1.036^{*}$ \\
Trend-squared & -0.001 & 0.001 & $0.999^{*}$ \\
\hline
\end{tabular}

Policy change variables (Bylaw and Bylaw trend), seasonality variables (Month and Month-squared), and overall trend variables (Trend and Trend-squared)

${ }^{*} p<0.10 ;{ }^{* *} p<0.05 ;{ }^{* * *} p<0.01$

confounding police activity changes that could account for the drop in pharmacy robberies. Additionally, the lack of an impact on Vancouver Island is likely because of the low counts of events, making it more difficult to find statistical evidence for such a change.

There are limitations that are important to acknowledge. First, because of the study design, it is difficult to make direct claims regarding causality. As noted above, however, the timing of the bylaw and security policy changes correspond very well with the drop on pharmacy robberies. One specific possibility here would be the independent impact of pharmacists, for example, individually tightening security on their own initiative, rather than being forced to through bylaw and security policy changes. Though possible, such a scenario is unlikely because a significantly large percentage of pharmacists/ pharmacies would have to undertake such independent initiatives almost simultaneously to have the effect found in the result, particularly for Vancouver. Second, we only consider police recorded crime data. Though this can be a concern in certain analyses because the percentage of criminal events reported to the police is $31 \%$ overall (Perreault 2015), the reporting rate of these robberies is very high because of insurance claims. And third, it is possible there are other confounding effects that we have not been able to account for in this evaluation. For example, there may have been a substitution to other illicit drug sources that corresponded with the by-law and security policy changes that led to a drop in pharmacy robberies. One possibility in this case relates to the opiate crisis in $\mathrm{BC}$ as a new drug fentanyl, sourced predominantly from China, also began to emerge in $\mathrm{BC}$ drug markets at this time (Global and Mail 2018). However, the timing of the impact of the current opiate crisis spiked approximately 1 year after the by-law and security policy changes. Furthermore, fentanyl is available in most pharmacies in $\mathrm{BC}$ and would likely be sought after by low-level drug dealers committing these robberies. ${ }^{9}$

In conclusion, it appears that the by-law and security policy changes had their intended effect in reducing pharmacy robberies either through an immediate drop (Vancouver) or a decreasing trend (Lower Mainland less Vancouver and the Interior). Given the volume of pharmacy robberies in Vancouver, statistically identifying an immediate drop is more likely because large magnitude decreases are easier to identify when the count of such events are greater; in areas with fewer pharmacy robberies, these drops are more likely to emerge, statistically, as a change in trend because it would take more time for any drops to emerge in the data that are not the result of random variation in the crime data. ${ }^{10}$ Thus, the evidence presented here provides support for the by-law and security policy changes implemented by the College of Pharmacists of $\mathrm{BC}$. These findings may have implications for other pharmacies in Canada. British Columbia has been experiencing the greatest volume of opiate-related deaths in Canada (Special Advisory Committee on the Epidemic of Opioid Overdoses 2018). As this use spreads to other areas of the country, the implementation of similar bylaw and security policy changes in other areas of Canada

\footnotetext{
${ }^{9}$ Correspondence with police personnel identified those often responsible for pharmacy robberies as low-level drug dealers.

10 There is also the possibility of differences in the implementation or awareness campaigns of the bylaw and security policy changes. However, we have no data to be able to identify and such effects.
} 
Table 4 Negative binomial results, full and final models, Interior

\begin{tabular}{lcll}
\hline & $\begin{array}{l}\text { Estimated } \\
\text { parameter }\end{array}$ & Std. error & $\begin{array}{l}\text { Relative } \\
\text { risk ratio }\end{array}$ \\
\hline Full model & & & \\
Bylaw & 0.039 & 1.279 & 1.041 \\
Bylaw trend & -0.226 & 0.121 & $0.798^{*}$ \\
Month & -0.331 & 0.227 & 0.718 \\
Month-squared & 0.021 & 0.018 & 1.021 \\
Number of days & -0.092 & 0.264 & 0.912 \\
Trend & 0.109 & 0.039 & $1.115^{* * *}$ \\
Trend-squared & -0.001 & 0.001 & $0.999^{* *}$ \\
Final model & & & \\
Bylaw trend & -0.211 & 0.128 & $0.810^{*}$ \\
Month & -0.079 & 0.046 & $0.924^{*}$ \\
Trend & 0.109 & 0.036 & $1.116^{* * *}$ \\
Trend-squared & -0.001 & 0.001 & $0.999^{* * *}$ \\
\hline Policy changevarible & &
\end{tabular}

Policy change variables (Bylaw and Bylaw trend), seasonality variables (Month and Month-squared), and overall trend variables (Trend and Trend-squared)

${ }^{*} \mathrm{p}<0.10$; ${ }^{* *} \mathrm{p}<0.05$; ${ }^{* * *} \mathrm{p}<0.01$

could be used to reduce levels of pharmacy robberies and burglaries and, potentially, reduce opportunities for access to these drugs in other areas.

\section{Abbreviations}

BC: British Columbia; COPS Office: Office of Community Policing Services, U.S. Department of Justice; CPTED: Crime Prevention through Environmental Design; RRR: relative risk ratio; SCP: situational crime prevention.

\section{Authors' contributions}

The first author designed the study. The first and second authors contributed to the data organization and analysis. All authors contributed to the writing. All authors read and approved the final manuscript.

\section{Author details}

${ }^{1}$ School of Criminology and Institute for Canadian Urban Research Studies, Simon Fraser University, 8888 University Drive, Burnaby, BC V5A 1S6, Canada. ${ }^{2}$ School of Criminology and Criminal Justice, Griffith University, Room 3.09, Social Sciences Building (M10), 176 Messines Ridge Road, Mt Gravatt, QLD 4122, Australia. ${ }^{3}$ Vancouver Police Department, 2120 Cambie St., Vancouver, BC V5Z 4N6, Canada. ${ }^{4}$ College of Pharmacists of British Columbia, 200-1765 West 8th Avenue, Vancouver, BC V6J 5C6, Canada.

\section{Acknowledgements}

We would like to thank Graham Farrell for initial guidance of this project.

\section{Competing interests}

Because the College of Pharmacists of British Columbia played no role in the design of the study and collection, analysis, or interpretation of data, the authors declare that they have no competing interests.

\section{Availability of data and materials}

Data cannot be shared due to confidentiality restraints.

\section{Funding}

Funding for this project was provided by the College of Pharmacists of British Columbia. This funding body played no role in the design of the study and collection, analysis, or interpretation of data.

\section{Publisher's Note}

Springer Nature remains neutral with regard to jurisdictional claims in published maps and institutional affiliations.

Received: 11 October 2018 Accepted: 3 January 2019

Published online: 16 January 2019

\section{References}

Amandus, H., Hunter, R., James, E., \& Hendricks, S. (1995). Reevalutation of the effectiveness of environmental designs to reduce robbery risk in Florida convenience stores. Journal of Occupational and Environmental Medicine, 37(6), 711-717.

BC Centre for Disease Control (2018). (2018). Opioid overdose emergency in B.C. Vancouver, BC: BC Centre for Disease Control.

Cameron, A. C.. \& Trivedi, P. K. (1990). Regression-based tests for overdispersion in the Poisson model. Journal of Econometrics, 46(3), 347-364.

Carman, T., \& Adhopia, V. (2018). More than half a million prescription drugs are stolen each year-and most are opioids. CBC News. https://www.cbc.ca/ news/canada/missing-drugs-pharmacies-part1-1.4708041. Accessed 09 October 2018.

Casteel, C., Peek-Asa, C., Howard, J., \& Kraus, J. (2004). Effectiveness of crime prevention through environmental design in reducing criminal activity in liquor stores: A pilot study. Journal of Occupational and Environmental Medicine, 46(5), 450-458.

Clarke, R. V. (1997). Introduction. In R. Clarke (Ed.), Situational crime prevention: Successful case studies (2nd ed., pp. 2-43). Monsey: Criminal Justice Press.

Clarke, R. V. (2017). Situational crime prevention. In R. Wortley \& M. Townsley (Eds.), Environmental criminology and crime analysis (2nd ed., pp. 286-303). London: Routledge.

Cornish, D., \& Clarke, R. (2003). Opportunities, precipitators, and criminal decisions: A reply to Wortley's critique of situational crime prevention. In M. Smith \& D. Cornish (Eds.), Theory for practice in situational crime prevention (pp. 41-96). Monsey, NY: Criminal Justice Press.

Cotter, A., Greenland, J., \& Karam, M. (2015). Drug-related offences in Canada, 2013. Ottawa: Canadian Centre for Justice Statistics.

Exum, M., Kuhns, J., Koch, B., \& Johnson, C. (2010). An examination of situational crime prevention strategies across convenience stores and fastfood restaurants. Criminal Justice Policy Review, 21(3), 269-295.

Farrell, G., \& Brantingham, P. J. (2013). The crime drop and the General Social Survey. Canadian Public Policy, 39(4), 559-580.

Farrell, G., Tseloni, A., Mailley, J., \& Tilley, N. (2011). The crime drop and the security hypothesis. Journal of Research in Crime and Delinquency, 48(2), 147-175.

Feeney, F. (1986). Robbers and decision-makers. In D. B. Cornish \& R. V. Clarke (Eds.), The reasoning criminal (pp. 53-71). New York: Springer-Verlag.

Felson, R. B., \& Staff, J. (2017). Committing economic crime for drug money. Crime \& Delinquency, 63(4), 375-390.

Fischer, B., \& Rehm, J. (2018). Revisiting the'paradigm shift' in opioid use: Developments and implications 10 years later. Drug and Alcohol Review, 37(S1), S199-S202.

Fraser, K., \& Viau, J. (2017). Pharmacy takes drastic security measures after recent robbery. CBC News. https://www.cbc.ca/news/canada/windsor/ adamo-pharmacy-windsor-essex-horrobin-police-security-1.4433849. Accessed 09 October 2018.

Gardner, W., Mulvey, E. P., \& Shaw, E. S. (1995). Regression analyses of counts and rates: Poisson, overdispersed Poisson, and negative binomial models. Psychological Bulletin, 118(3), 392-404.

Global \& Mail. (2018). How Globe and Mail reporters traced the rise of fentanyl. Globe \&Mail. https://www.theglobeandmail.com/news/investigations/ how-globe-and-mail-reporters-traced-the-rise-of-fentanyl/article295 69921/. Accessed 09 October 2018.

Global Commission on Drug Policy. (2017). The opioid crisis in North America. Geneva: Global Commission on Drug Policy.

Groff, E. R., \& Lockwood, B. (2014). Criminogenic facilities and crime across street segments in Philadelphia uncovering evidence about the spatial extent of facility influence. Journal of Research in Crime and Delinquency, 51(3), 277-314. 
Harries, K. D., Stadler, S. J., \& Zdorkowski, R. T. (1984). Seasonality and assault: explorations in inter-neighborhood variation, Dallas 1980. Annals of the Association of American Geographers, 74(4), 590-604.

Hendricks, S., Landsittel, D., Amandus, H., Malcan, J., \& Bell, J. (1999). A matched case-control study of convenience store robbery risk factors. Journal of Occupational and Environmental Medicine, 41(11), 995-1004.

Henriques-Gomes, L. (2018). Fentanyl use surges in Australia, drug monitoring program finds. The Guardian. https://www.theguardian.com/austr alia-news/2018/oct/09/fentanyl-use-surges-in-australia-drug-monitoring -program-finds. Accessed 09 October 2018.

Hodgkinson, T., Andresen, M. A., \& Saville, G. (2018). "Staying out that public housing": Examining the role of security measures in public housing design. Crime Prevention \& Community Safety: An International Journal, 20(2), 99-112.

Hunter, R. D., \& Jeffrey, C. R. (1997). Preventing convenience store robbery through environmental design. In R. V. Clarke (Ed.), Situational crime prevention: Successful case studies (2nd ed., pp. 191-199). Monsey, NY: Criminal Justice Press.

Jeffrey, C. R. (1971). Crime prevention through environmental design. Thousand Oaks: Sage Publications.

LaFree, G. (1999). Declining violent crime rates in the 1990s: Predicting crime booms and busts. Annual Review of Sociology, 25, 145-168.

LaVigne, N., \& Wartell. J. (2015). Robbery of pharmacies. Problem-Oriented Guides for Police, Problem-Specific Guide No. 73. Washington, DC: Office of Community Oriented Policing Services.

Levitt, S. D. (2004). Understanding why crime fell in the 1990s: Four factors that explain the decline and six that do not. Journal of Economic Perspectives, 18(1), 163-190.

Linning, S. J., Andresen, M. A., Ghaseminejad, A. H., \& Brantingham, P. J. (2017). Crime seasonality across multiple jurisdictions in British Columbia, Canada. Canadian Journal of Criminology and Criminal Justice, 59(2), 251-280.
MacDonald, J., \& Lattimore, P. (2010). Count models in criminology. In A. Piquero \& D. Weisburd (Eds.), Handbook of quantitative criminology (pp. 683-698). New York: Springer.

Osgood, D. W. (2000). Poisson-based regression analysis of aggregate crime rates. Journal of Quantitative Criminology, 16(1), 21-44.

Perreault, S. (2015). Criminal victimization in Canada, 2014. Ottawa, ON: Canadian Centre for Justice Statistics, Statistics Canada.

Piehl, A. M., Cooper, S. J., Braga, A. A., \& Kennedy, D. M. (2003). Testing for structural breaks in the evaluation of programs. Review of Economics and Statistics, 85(3), 550-558.

Reid, A. A., \& Andresen, M. A. (2014). An evaluation of CCTV in a car park using police and insurance data. Security Journal, 27(1), 55-79.

Smith, M. J., Clarke, R. V., \& Pease, K. (2002). Anticipatory benefits in crime prevention. Crime Prevention Studies, 13, 71-88.

Special Advisory Committee on the Epidemic of Opioid Overdoses (2018). National report: Apparent opioid-related deaths in Canada (January 2016 to March 2018). Web-based Report. Ottawa, ON: Public Health Agency of Canada.

Waller, I. (2006). Less law, more order: The truth about reducing crime. Westport, CT: Praeger.

Welsh, B. C., \& Taheri, S. A. (2018). What have we learned from environmental criminology for the prevention of crime? In G. J. N. Bruinsma \& S. D. Johnson (Eds.), Oxford handbook of environmental criminology (pp. 757-775). New York: Oxford University Press.

Welsh, B. C., Zimmerman, G. M., \& Zane, S. N. (2018). The centrality of theory in modern day crime prevention: Developments, challenges, and opportunities. Justice Quarterly, 35(1), 139-161.

Whelan, A. (2018). Fentanyl is killing more and more people in Pennsylvania. The Inquirer, Daily News. http://www2.philly.com/philly/health/addic tion/fentanyl-is-killing-more-and-more-people-in-pennsylvania-20180 821.html. Accessed 09 October 2018.
Ready to submit your research? Choose BMC and benefit from:

- fast, convenient online submission

- thorough peer review by experienced researchers in your field

- rapid publication on acceptance

- support for research data, including large and complex data types

- gold Open Access which fosters wider collaboration and increased citations

- maximum visibility for your research: over 100M website views per year

At BMC, research is always in progress.

Learn more biomedcentral.com/submissions 